\title{
The Sheffield outreach teaching programme
}

\author{
M. Smith, ${ }^{1}$ M. A. Lennon ${ }^{2}$ and P. G. Robinson ${ }^{3}$
}

VERIFIABLE CPD PAPER

IN BRIEF

- Sheffield students now spend six months working in outreach primary care - half this time in general practice settings.

- Students gain considerable 'real-life' clinical experience leading to enhanced confidence and competence.

- The scheme was piggy-backed onto existing dental facilities and its running costs are met from existing resources.

Sheffield's School of Clinical Dentistry has developed a year-round dental outreach teaching programme of 20 weeks for each student in two or three of six already established general practices and five PCT clinics. On the programme, under local supervision, students provide comprehensive care for patients and complete associated projectwork. This paper first describes the development and management of the programme then the learning experiences of recent students.

\section{INTRODUCTION}

The vast majority of UK dental students progress to working in primary care, most as general dental practitioners (GDPs). These students should have substantial experience of assisted operation and working in a greater dental team and an understanding of routine clinical practice in primary care. ${ }^{1}$ Dental hospitals struggle to provide these experiences but outreach teaching can enhance training in these aspects. ${ }^{1-3}$ The value of situated learning (amidst a workplace team) has been embraced by dental educators establishing new dental curricula to reduce the problematic transfer of learning to new settings. ${ }^{4,5}$ In this context the School of Clinical Dentistry at the University of Sheffield has worked over the last seven years with the support of local Primary Care Trusts (PCTs) and leading salaried dentists and GDPs to develop a substantial dispersed outreach teaching programme for undergraduates and hygiene and therapy (H\&T) students. The programme's development and management are described in this paper followed by a summary of recent students' outreach learning experiences.

"2,3 Dental Public Health, School of Clinical Dentistry, University of Sheffield, Claremont Crescent, Sheffield, S10 2TA

${ }^{*}$ Correspondence to: Dr Michael Smith

Email:michael.smith@sheffield.ac.uk

\section{Refereed Paper}

Accepted 17 June 2010

DOI: 10.1038/sj.bdj.2010.1038

${ }^{\oplus}$ British Dental Journal 2010; 209: 513-520

\section{INCEPTION}

Early in the new millennium guidance to dental schools indicated that purely hospital-based training was unlikely to provide sufficient appropriate experience for entrants to the profession, who would probably work in primary care, mainly general practice. ${ }^{1,6}$ At this time the School started developing partnerships with local primary care trust dental services (PCTDS) and, if practicable, selected general dental practices, to create training opportunities in existing services. The aims of the programme were agreed at an early stage and reflected the specialism of those involved (Fig. 1).

Appointing an outreach programme manager (MAL) brought experience from established outreach programmes..$^{7-9}$ The head of an academic department (PGR) provided direction. An administrator and evaluator (MS) completed the outreach team.

\section{Proving and the decision to adopt an expanded programme}

In 2003 a six-week pilot scheme for 20 Sheffield students evaluated students' and hosts' perceptions. ${ }^{10,11}$ Pointers for subsequent development were the importance of individual nursing support and having sufficient students in each location to maintain service volume. Then in 2004 a randomised controlled trial gave firm evidence of the educational benefits of this adjunct to hospital training. ${ }^{12,13}$ Secure in this knowledge and faced with a request to expand its intake, the School planned a six-month programme of outreach for all senior students. ${ }^{14}$ This possibility became feasible as guidance changed encouraging the use of these primary care settings for training. ${ }^{1,15}$

At this and other key stages in the programme's development the evidence and rationale were made explicit and openly discussed within the School as there was initial scepticism regarding outreach among School staff, as noted elsewhere. ${ }^{16}$ Experience of the programme's effect on students has convinced many staff that the programme has achieved its aims.

\section{Creating the facilities}

The requisite capital to develop 31 additional outreach training surgeries amounted to £2.3 million and was jointly funded by the Higher Education Funding Council for England $(£ 834,000)$ and the Yorkshire and the Humber NHS Strategic Health Authority (£1.5 million). With funding secured in 2006, supportive local PCTs agreed to incorporate training surgeries in their expansion plans and also invited all local GDPs with an interest in the scheme to discuss the possibility of hosting students. Up to $£ 1,500$ was available to each practice to support the development of its bid. Of the 208 dental providers contacted and others who heard of the scheme, 24 expressed interest and 20 practices attended briefing meetings. Eleven practices submitted between them 14 bids for scrutiny by a panel (Fig. 2). 
Five general dental practices were subsequently selected to develop 19 additional surgeries. The selection criteria are listed in Figure 3. Costing between $£ 60,000$ and $£ 104,000$ per surgery (average £88,000) they were available within a year. Likewise selected were 11 PCTDSs surgeries across four locations costing on average $£ 98,000$. Salaried services typically took almost two years to implement plans.

Formal agreements committed the School to the capital funding, described the facilities required and made explicit an expectation of at least ten years' commitment to hosting students. Further agreements set out the educational expectations of the hosts and the support and recurrent funding expectations of the School.

Before starting, outreach staff attended School-based training sessions that included shadowing dental hospital supervisors, meeting experienced hosts and discussing students' capabilities, the programme's aims and its intended learning experiences. Over 50 supervising dentists gained the honorary clinical lecturer status required to host students and have all subsequently attended annual training days.

Together with facilities developed earlier this expansion provided a total of 38 surgeries for student use throughout the year: 22 in general practices across six locations and 16 in PCTDSs across five locations.

\section{Management structure}

The management structure devised for the programme followed the Sheffield norm with the addition of a high level Steering Group having representation from the SHA, the PCT, outreach location managers, the Dean, school administrator and outreach team (Fig. 4). This steering group ensured key stakeholders' contributions were coordinated. It will be dissolved as the programme reaches maturity.

At an operational level, clinical managers' meetings bring together senior staff from each location and the School's outreach team three times a year to review recent reports of activity and forward plan.

To ensure the student perspectives contribute to programme development, reports of systematically gathered student feedback (see quality assurance below) are considered alongside students' narratives by a Working Party of academic managers,

The programme's aims will be achieved across three placements by means of clinical practice; tutorials and preparatory lectures; a practice environment and visits into the community. Students are encouraged to make links between their experiences on the programme and their lectures on dental public health and primary dental care, and with other parts of their course.

Each placement on the outreach programme is unlikely to provide opportunities for students to achieve all the objectives. However, the three placements taken together should allow them to achieve all objectives The four objectives marked + apply to undergraduate students only.

\section{Professional responsibility}

Aim: To encourage students to appreciate the ethical responsibility of dental professionals for the oral health of the whole community.

Objectives: In particular students should have:

- An awareness of the changing needs and expectations of the community

- An awareness of the dental profession's wider role eg in health promotion, emergency services and domiciliary care

- An awareness of links with other services within and without health services

- An awareness of the overriding responsibility to protect and promote general health.

\section{Public health dentistry}

Aim: To increase student understanding of the principles and particularly the practice of

public health dentistry.

Objectives: In particular students should have:

- Understood the difference between need and demand +

- Understood the principles and uses of dental epidemiology +

- Understood the principles and uses of oral health promotion as applied in primary care

- Recognised the different ways dental services can be set up to meet community needs and appreciated the strengths and weaknesses of the different approaches

- An awareness of the relative influence of the environment (physical, economic and social) on the oral health of the community and on the prognosis of dental care.

\section{Practice environment}

Aim: To encourage students to appreciate the responsibilities and requirements of the practice environment.

Objectives: Specifically students should have:

- Gained an appreciation of the organisation of the clinical environment, including health and safety aspects

- Appreciated the needs for time management and setting priorities with regard to the planning of patient care

- Appreciated the role of clinical governance and its application in the practice environment

- Appreciated the importance of teamwork within the expanded dental team.

\section{Further development of clinical skills}

Aim: To consolidate awareness and develop skills in the provision of comprehensive dental care for a range of patient groups.

Objectives: In particular students should have:

- Developed the skills of patient management, including communication skills

- Developed the skills of diagnosis and treatment planning +

- Experienced and gained skills in team dentistry

- Experienced and gained skills in referral of prescribed dental treatment between team members +

- Developed skills in the use of preventive dentistry techniques

- Further developed the skills of clinical operative dentistry in a primary dental care environment.

\section{Fig. 1 Aims of the programme}

$\begin{array}{ll}\text { From the SHA } & \text { Senior manager (Chair) } \\ \text { From the local PCTs } & \text { Dental public health consultants } \\ & \text { Clinical director } \\ & \text { Finance officer } \\ \text { From the Dental School } & \text { Academics } \\ & \text { Clinicians } \\ & \text { Outreach administrator }\end{array}$

Fig. 2 Membership of the panel scrutinising bids to develop training facilities

the outreach team and representatives of students and outreach managers.

\section{Recurrent financing}

The recurrent funding model assumes that the PCT will continue to fund the contracted dental activity and that the University Dental Hospital would fund the additional costs resulting from hosting three or four students.

The initial model for hosting students was developed in 2005 by an SHA/PCT/ School collaboration. That model assumes a PCTDS hosts three students 'piggy-backed' onto an existing financially viable service where one unit (surgery, dentist and nurse) 
stop their usual work (Fig. 5). With three training surgeries added, an extra three nurses are required to host four students under the supervision of the displaced dentist. The salaries of the three nurses, additional administration and liaison with the School together account for about 70\% of the additional costs. Those costs totalled $£ 28,760$ pa per surgery if operating five days a week or $£ 23,000$ pa if four days. A modification of the model for GDP settings found broadly similar overall costs of about £26,000 pa per surgery at 2009 prices (Fig. 6).

Based on experience, the models assume the combined activity of the 3 or 4 students is roughly equivalent to the dentist who stopped clinical working to supervise them. ${ }^{3,5,17}$ Unit of Dental Activity (UDA) data for the four general practices hosting four students during 2008 show students, including HetT students, typically achieved a mean of 15 UDAs per half day session (annualised range 11-15 per session). This matches the 15 UDAs per session suggested as normal for an ex-PDS contract dentist by senior PCT staff and a dental corporation's senior executive. It is financially reassuring that the students' activity matches that of a normal dentist allowing the contracted UDA load to be substantially achieved. However, PCT staff generally reassured prospective GDP hosts that an understanding approach would be taken if there were modest shortfalls in the contract delivery.

The annual revenue to reimburse the hosts' additional costs totals about $£ 1,000,000 \mathrm{pa}$. This is funded in the ratio of the BDS and HetT students' use of surgeries, with approximately $£ 800,000$ pa channelled from dental SIFT and £200,000 pa from H\&T funding. An additional £22,000 pa from SIFT covers undergraduates' travel allowances and about $£ 8,000$ pa funds training, reprographics, meeting costs, etc. These costs total $£ 1,030,000$ pa. The proportion of annual SIFT per undergraduate allocated to the outreach programme is somewhat less than the proportion of the year each student attends outreach.

\section{Administration}

An operation spanning almost 20 organisations demands careful administration. Students' details and interests are gathered to inform allocations to placements. Students'
The building and fitting out of surgeries are costed with quotations and estimates

The existing practice/service has a record of meeting health and safety and other quality standards

The development is in a location with the ability to address issues of inequalities and need

The service/practice has demonstrated commitment to the NHS

The service/practice has a record of providing a high standard of NHS care

There is evidence of educational potential

The addition of student facilities will not unbalance existing services

Value for money based on the cost per surgery.

\section{Fig. 3 Selection criteria for bids to develop training facilities}

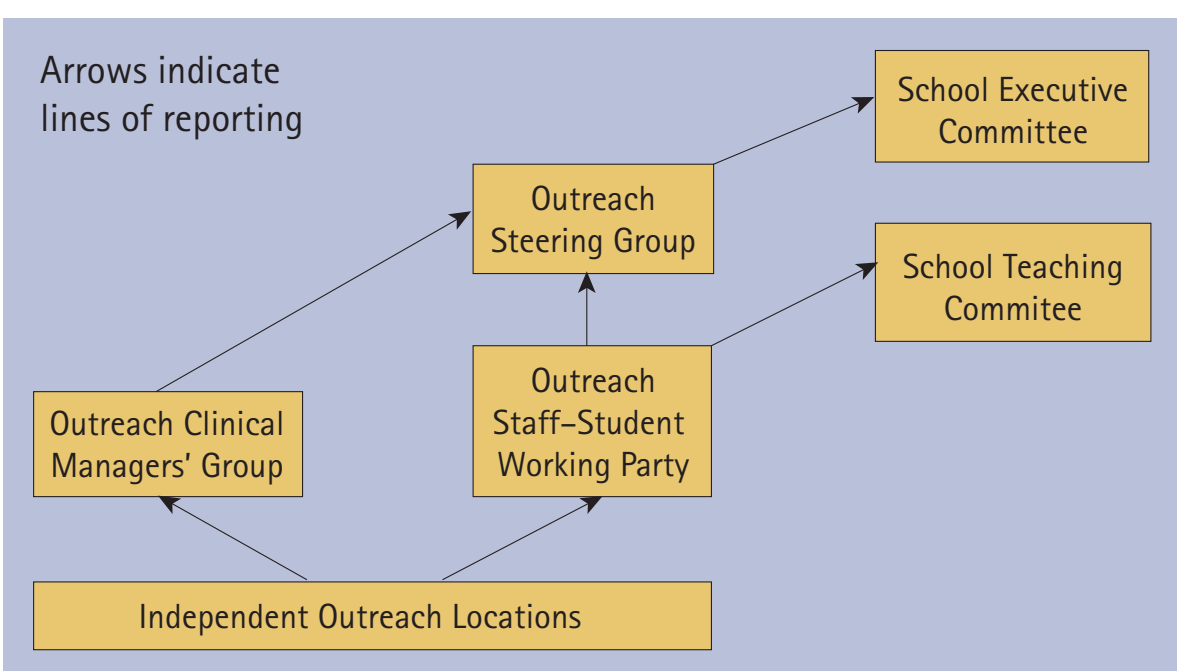

Fig. 4 The programme's management structure

$\begin{array}{lllr}\text { Pay costs: } & \text { Staff Description } & \text { WTE } & \text { Gross Cost (£) } \\ & \text { Senior Dental Officer } & 0.1 & 6,794 \\ \text { Dental Whitley supplement } & 3.0 & 5,340 \\ \text { Dental Nurse } & 2.0 & 42,404 \\ \text { Senior Nurse/Manager } & 0.1 & 2,566 \\ \text { Secretarial } & 0.2 & 3,624 \\ & & \text { Total } £ 60,728 \text { pa }\end{array}$

Explanatory notes

WTE, whole time equivalent

2005/2006 costs and prices

Senior Dental Officer manages the programme in one session per week

Dental Officer's Whitley supplements (a) 3 required for absence cover and (b) only part of week spent teaching to maintain own clinical skills

Dental Nurse - two additional nurses needed to join existing nurse.

Senior Dental Nurse/Operational Manager for liaison and timetabling.

Non- Pay Costs: Description

Dental equipment

Cost $(€)$

13,230

Other direct non pay $\quad 5,400$

Corporate overheads

4,118

Total $€ 25,548 \mathrm{pa}$

\section{Explanatory notes}

Dental Equipment costs are annual replacement cost.

Estate costs - costs such as utilities, rent, building maintenance etc. are included. Costed as if part of a LIFT scheme (NHS LIFT is a vehicle for external capital funding of a project for which a recurrent payment is made over a fixed period).

Other direct non-pay includes equipment repairs/maintenance, non-pay staff costs, gloves, etc. Corporate overheads represent a 5\% contribution.

Assumes the 4 students' work in the 3 surgeries is equivalent in volume to that otherwise completed by the supervising dentist.

Total Costs:

For a 3 surgery, 4 student unit $£ 86,276 \mathrm{pa}$ Per surgery $€ 28,760 \mathrm{pa}$

Fig. 5 A financial model for outreach in community services 
Table 1 Outreach clinical experience of dental undergraduates

\begin{tabular}{|c|c|c|c|c|c|}
\hline & Minimum & 1st Quartile & Mean & 3rd Quartile & Maximum \\
\hline \multicolumn{6}{|l|}{ RESTORATIVE DENTISTRY (ADULTS) } \\
\hline New patient assessment $\mathcal{C}$ treatment planning & 14 & 48 & 75 & 98 & 207 \\
\hline Restorative review & 1 & 21 & 62 & 91 & 180 \\
\hline Amalgams & 30 & 60 & 74 & 88 & 170 \\
\hline Composites & 21 & 46 & 59 & 68 & 127 \\
\hline Glass ionomers & 9 & 20 & 33 & 44 & 74 \\
\hline Single rooted endodontics & 0 & 3 & 7 & 9 & 22 \\
\hline Multi rooted endodontics & 0 & 2 & 6 & 8 & 21 \\
\hline Inlays/onlays & 0 & 0 & 0 & 0 & 3 \\
\hline Crowns & 0 & 3 & 5 & 7 & 13 \\
\hline Veneers & 0 & 0 & 0 & 1 & 3 \\
\hline Bridges & 0 & 0 & 1 & 1 & 3 \\
\hline Complete dentures & 0 & 1 & 4 & 5 & 8 \\
\hline Acrylic partial dentures & 0 & 4 & 8 & 10 & 15 \\
\hline $\mathrm{Co} / \mathrm{Cr}$ partial dentures & 0 & 0 & 1 & 1 & 3 \\
\hline Other prosthetics - reline/addition/repair & 0 & 2 & 6 & 8 & 31 \\
\hline Periodontal review & 0 & 1 & 4 & 6 & 14 \\
\hline Scaling and polishing & 32 & 51 & 74 & 93 & 198 \\
\hline Root surface debridement & 0 & 5 & 11 & 14 & 34 \\
\hline \multicolumn{6}{|l|}{ ORAL SURGERY/MEDICINE (ADULTS) } \\
\hline Simple forceps extractions & 27 & 45 & 67 & 84 & 109 \\
\hline Minor oral surgery procedures & 0 & 0 & 1 & 2 & 5 \\
\hline Cases assisted & 0 & 0 & 1 & 0 & 7 \\
\hline Cases observed & 0 & 0 & 0 & 1 & 3 \\
\hline
\end{tabular}

ASSESSMENT \& CASUALTY (ADULTS)

\begin{tabular}{|c|c|c|c|c|c|}
\hline Emergency patient assessments & 0 & 21 & 40 & 54 & 109 \\
\hline Emergency patients treated & 0 & 16 & 34 & 48 & 102 \\
\hline \multicolumn{6}{|c|}{ SEDATION (ADULTS OR CHILDREN) } \\
\hline IV Sedation administered & 0 & 0 & 0 & 0 & 2 \\
\hline IV Patients treated & 0 & 0 & 0 & 0 & 1 \\
\hline IV Patients observed & 0 & 0 & 0 & 0 & 4 \\
\hline IS (RA) patients treated & 0 & 0 & 0 & 0 & 3 \\
\hline IS (RA) patients observed & 0 & 0 & 0 & 0 & 4 \\
\hline IS (RA) sedation administered & 0 & 0 & 0 & 0 & 3 \\
\hline \multicolumn{6}{|c|}{ RADIOLOGY (ADULTS OR CHILDREN) } \\
\hline Extra oral radiographs taken & 0 & 1 & 2 & 6 & 10 \\
\hline & & & & \multicolumn{2}{|c|}{ Continues on page 518} \\
\hline
\end{tabular}




\section{EDUCATION}

\begin{tabular}{|c|c|c|c|c|c|}
\hline \multicolumn{6}{|l|}{ Continued from page 517} \\
\hline & Minimum & 1st Quartile & Mean & 3rd Quartile & Maximum \\
\hline Intra oral radiographs taken & 30 & 99 & 136 & 167 & 249 \\
\hline \multicolumn{6}{|l|}{ CHILD DENTAL HEALTH } \\
\hline Orthodontic Assessment & 0 & 0 & 1 & 2 & 8 \\
\hline Removable appliance adjust/fit & 0 & 0 & 3 & 3 & 51 \\
\hline Fixed appliance adjust/fit & 0 & 0 & 6 & 6 & 50 \\
\hline Paediatric assessment & 11 & 30 & 41 & 52 & 85 \\
\hline Fissure sealant & 3 & 14 & 26 & 34 & 96 \\
\hline $\mathrm{OHI} /$ diet advice & 0 & 7 & 21 & 28 & 125 \\
\hline Topical fluoride application & 0 & 3 & 7 & 10 & 32 \\
\hline Amalgam & 0 & 4 & 9 & 14 & 27 \\
\hline Composite & 0 & 4 & 7 & 9 & 22 \\
\hline Glass ionomer restoration & 1 & 7 & 13 & 17 & 37 \\
\hline Stainless steel crown & 0 & 0 & 0 & 0 & 3 \\
\hline Pulp therapy - primary tooth & 0 & 0 & 1 & 2 & 6 \\
\hline Endo treatment - permanent tooth & 0 & 0 & 1 & 2 & 7 \\
\hline Trauma management & 0 & 0 & 1 & 1 & 4 \\
\hline Extractions & 0 & 3 & 7 & 9 & 23 \\
\hline \multicolumn{6}{|l|}{ REFERRALS (ADULTS OR CHILDREN) } \\
\hline Patient referrals to DCPs (inc. H\&t students) & 5 & 8 & 18 & 23 & 73 \\
\hline Referral to consultant or specialist & 0 & 3 & 5 & 7 & 17 \\
\hline \multicolumn{6}{|l|}{ Miscellaneous } \\
\hline Number of appointments/treatment episodes & 284 & 422 & 461 & 507 & 616 \\
\hline
\end{tabular}

\section{Clinical experience}

Table 1 summarises undergraduates' clinical experience across the programme. Compared to UK dental schools' expectations $^{19,20}$ (eg typically for about 70 plastic restorations) this experience is broad and extensive, though mainly in the more commonplace procedures. Individual students' experiences depend on their competence, pre-outreach experience and combination of placements, though attending three placements reduces overall variation from this last factor. Differences between typical experiences in the general practice and salaried settings taken as a whole are relatively small $(<30 \%)$ except for plastic restorations which are 60\% more common in general practice. Totals for H\&T students' (Table 2) are smaller reflecting their shorter time at placements.

Providing care in a genuine working environment provides valuable opportunities for learning beyond improving skills and widening experience. Three pieces of student project work were introduced to make greater use these opportunities and develop insights into the realities of both service and patients' lives. All operate successfully and, together with outreach staff assessments of students' skills, contribute to final examination marks.

\section{Project work}

BDS students complete one project in each placement. Firstly, students link community-level indicators of health to case studies selected from their patients. Emphasis is placed on the social aspects of the patients' histories and how these affect treatment planning. This project is based on a Liverpool model with the addition of a reflective component, and has proved effective in developing appreciation of the relevance of social circumstances to treatment planning. ${ }^{8,12}$ Students have commented on the lasting effect of the insights gained from this project on their subsequent treatment planning.

The audit project completed on second placement sees students selecting an aspect of service, searching for appropriate standards, designing, conducting and reporting the audit then suggesting any action that 


\begin{tabular}{|c|c|c|c|c|c|}
\hline & Minimum & 1st Quartile & Mean & 3rd Quartile & Maximum \\
\hline \multicolumn{6}{|l|}{ ADULTS RESTORATIVE DENTISTRY } \\
\hline White restorations & 11 & 32 & 42 & 50 & 76 \\
\hline Amalgam restorations & 15 & 33 & 43 & 56 & 94 \\
\hline Preventative Resin & 0 & 3 & 7 & 9 & 35 \\
\hline Temporary dressings & 0 & 1 & 4 & 5 & 11 \\
\hline Fissure sealant & 0 & 4 & 7 & 10 & 21 \\
\hline \multicolumn{6}{|l|}{ ADULT PERIODONTAL DENTISTRY } \\
\hline Review/Indices & 3 & 9 & 22 & 31 & 80 \\
\hline Oral Health Instruction (OHI) & 13 & 31 & 53 & 69 & 123 \\
\hline Scale and Polish & 42 & 66 & 80 & 93 & 129 \\
\hline Root Surface Debridement & 2 & 11 & 17 & 20 & 49 \\
\hline Locally Applied Antimicrobials & 0 & 0 & 1 & 1 & 6 \\
\hline Desensitising & 0 & 4 & 8 & 11 & 32 \\
\hline \multicolumn{6}{|l|}{ OTHER ADULT PROCEDURES } \\
\hline Infiltration & 14 & 39 & 51 & 63 & 77 \\
\hline ID Block & 15 & 21 & 26 & 31 & 49 \\
\hline Alginate & 0 & 2 & 3 & 4 & 15 \\
\hline Radiographs & 4 & 15 & 21 & 25 & 52 \\
\hline Temporary replacement of crowns & 0 & 5 & 11 & 17 & 33 \\
\hline \multicolumn{6}{|l|}{ TREATMENT FOR CHILDREN } \\
\hline Fissure Sealant & 6 & 14 & 31 & 46 & 81 \\
\hline Simple restoration & 7 & 18 & 24 & 29 & 54 \\
\hline Complex restoration (eg steel crown) & 0 & 0 & 0 & 0 & 1 \\
\hline Preventive treatment (eg Duraphat) & 1 & 5 & 12 & 18 & 52 \\
\hline LA Deciduous Tooth Extractions & 0 & 1 & 2 & 4 & 6 \\
\hline GA Deciduous Tooth Extractions & 0 & 0 & 0 & 0 & 0 \\
\hline Pulpotomies & 0 & 0 & 1 & 1 & 3 \\
\hline LA given & 2 & 8 & 11 & 15 & 21 \\
\hline
\end{tabular}

might be taken. Such a practical approach is restricted to a few narrow projects in the dental hospital. Students value learning a skill they consider important for their working futures.

By the start of their third placement most undergraduates have completed 100 restorations and are encouraged to concentrate on more advanced work and treatment planning while developing their team leadership skills. ${ }^{21}$ Under supervision, undergraduates assess patients and refer appropriate work to H\&T students. The project work has dental students identifying the permitted duties of a therapist and the experience and competence of their placement's therapy student. Next the BDS student plans, refers and supports appropriate developmental experiences for the therapy student while they are on placement together before reviewing the therapist's skill development at the end of the placement. Undergraduates also investigate and report the continuing professional development arrangements of their dental nurse. Finally, students reflect on their team leadership role based on these experiences and the therapy student concerned also provides feedback to the undergraduate. This project is valued for the understanding it develops of other team members' roles and needs.

Markers and outreach supervisors observe clear evidence of learning across these established and discriminating practice-based projects. 


\section{Wider learning}

Students regularly report unplanned opportunistic learning in other areas, for example, on the practicalities of running a practice, links with other services and the history and politics of delivering dental services. Lunchtime discussions with placement staff explore perspectives on dental issues and career trajectories. Perhaps most pleasingly, students report that the placements, though initially nerve wracking, renew their interest in dentistry and convince them that, despite having much still to learn, they will cope on qualification. Many delight in being accepted into the dental team and attribute acceptance in part both to having demonstrated their competence and to block attendance.

\section{CONCLUSION}

An outreach programme dispersed into pre-existing primary care establishments, including general practices, is feasible though its development and operation require careful management. Close partnerships with PCTs, SHAs and practitioners are needed from the planning onwards. Supervising just three or four students while having educational benefits has been supposed to make dispersed outreach more expensive than other options but this has not proved to be the case here. ${ }^{22}$

The placements provide ample and varied opportunities for clinical experience and learning across a broad front. Structuring learning via projects guides students' observations and is well suited to situated learning. The teamwork project in particular is innovative in developing undergraduates' teamworking and leadership in situ. Outside the surgery, students social acceptance into dental teams encourage additional learning and develops professional self-identity ie 'learning to be a dentist.,5,23
This outreach programme differs from those recently developed at Cardiff and Leeds which use larger purpose-built units with a staffing ratio around 8:1 and which may not share the same ethos of primary care. ${ }^{24,25}$ Those programmes and Newcastle's and Manchester's students are hosted in PCT community services and students attend for one or two sessions weekly or fortnightly. ${ }^{7,26}$ In contrast the Sheffield programme involves block attendance in smaller units 'piggybacked' onto existing services, half of which are general practices to give greater breadth of experience. This dispersed model of outreach is commended to other schools as an efficient and effective means of providing experience in delivering primary care. The School, students and hosts are convinced this programme trains a workforce better prepared to join the profession.

The recurrent funding models were developed from an earlier Liverpool version. The developers were David Brown, Senior Finance Manager of South Yorkshire Strategic Health Authority, and Peter Bateman of the Sheffield PCT. The School acknowledges the contributions of the managers and principals of the hosts in developing the programme, especially those from Derbyshire, Doncaster, East Riding of Yorkshire, Sheffield and Rotherham PCTs, High Green, Lidster and Middleton, Genesis Lynton House, The Mount, Taptonville House and Thompson and Thomas dental practices. Staff of Birmingham, Cardiff, Manchester, Newcastle and Liverpool dental schools shared their outreach experiences to inform Sheffield's planning.

1. General Dental Council. The first five years: $a$ framework for undergraduate dental education, 2nd ed. London: GDC, 2002

2. General Dental Council. General Visitation 2003-2005: General Report of the Visitors to the Undergraduate Dental Degree Programmes and Final Examinations in the United Kingdom. London: GDC, 2006.

3. Eaton K. Outreach teaching - coming soon to a practice near you. Prim Dent Care 2005; 12: 115-116.

4. Cure R J, Ireland R S. The development of an outreach training programme in orthodontics. Br Dent J 2008; 204: 631-634

5. McHarg J, Kay E J. The anatomy of a new dental curriculum. Br Dent J 2008; 204: 635-638.

6. Department of Health. NHS Dentistry: options for change. London: Department of Health, 2002, publication no. 28742.

7. Holloway P J, Dixon P A. Extra-mural experience for undergraduate dental students. Br Dent J 1977; 143: 146-150.

8. Harris R V, Dailey Y, Lennon M A. Recording and understanding social histories by dental undergraduates in a community-based clinical programme. Eur J Dent Educ 2003; 7: 34-40.

9. Lennon M A, Ireland R S, Tappin J et al. The persona dental service as a setting for an undergraduate clinical programme. Br Dent J 2004; 196: 419-422.

10. Smith M, Lennon M A, Brook A H, Robinson P G. Perspectives of staff on student outreach placements. Eur J Dent Educ 2006; 10: 44-51.

11. Smith M, Lennon M A, Brook A H et al. Student perspectives et al. on their recent dental outreach placement experiences. Eur J Dent Educ 2006; 10: 80-86.

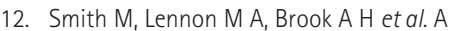
randomised controlled trial of the effect of outreach placement on treatment planning by dental students. Br Dent J 2006; 201(Educ sup): 27-31.

13. Smith M, Lennon M A, Brook A H et al. A randomized controlled trial of outreach placement's effect on dental students' clinical confidence. J Dent Educ 2006; 70: 566-570.

14. Lennon M A. Expanding dental undergraduate clinical outreach programmes into general dental practice. Community Dent Health 2007; 24: 2-3.

15. General Dental Council. Developing the dental team: curricula frameworks for registrable qualifications for professionals complementary to dentistry. London: GDC, 2004.

16. Elkind A. Outreach teaching: is this the future for dental education? Br Dent J 2002; 193: 111-112.

17. Rock W P, Foster T D. A programme of clinical work by undergraduate dental students in community dental clinics. Br Dent J 1982; 152: 12-14.

18. The Quality Assurance Agency for Higher Education Code of practice for the assurance or quality and standards in higher education, Section 9: Placement Learning. Gloucester: QAA, 2001.

19. Lynch $C D$, Allen P F. The teaching of removable partial dentures in Ireland and the United Kingdom. Br Dent J 2007; 203: E17.

20. Youngson C C, Molyneux L E, Fox K et al. Undergraduate requirements in restorative dentistry in the UK and Ireland. Br Dent J 2007; 203(5 Supp): 9-14.

21. General Dental Council. Principles of dental team working. London: GDC, 2006.

22. Elkind $A$, Watts $C$, Qualtough $A$ et al. The use of outreach clinics for teaching undergraduate restorative dentistry. Br Dent J 2007; 203: 127-132.

23. Cope $P$, Cuthbertson $P$, Stoddart B. Situated learning in the practice environment. J Adv Nurs 2000; 31: 850-856.

24. Lynch C D, Ash P J, Chadwick B L. Student perspectives and opinions on their experience at an undergraduate outreach dental teaching centre at Cardiff: a 5-year study. Eur J Dent Educ 2010; 14: 12-16.

25. Craddock H L. Outreach teaching - the Leeds experience: reflections after one year. Br Dent $J$ 2008; 204: 319-324.

26. Hind V, Waterhouse P J, Maguire A et al. Developing a primary dental care outreach (PDCO) course - part 1: practical issues and evaluation of clinical activity. Eur J Dent Educ 2008; 12: 8-16. 